\title{
Effectiveness of cervical length screening by transvaginal sonography and use of progesterone for preventing preterm labour
}

\author{
Snehal S. Dhobale ${ }^{1 *}$, Meena Satia ${ }^{2}$
}

\begin{abstract}
${ }^{1}$ Consultant Reproductive Medicine Origin International Fertility Centre, Thane, Maharashtra, India
${ }^{2}$ Department of Obstetrics and Gynaecology, Seth Gordhandas Sunderdas Medical College and King Edward VII Memorial Hospital, Mumbai, Maharashtra, India
\end{abstract}

Received: 24 June 2016

Accepted: 12 July 2016

\section{*Correspondence:}

Dr. Snehal S. Dhobale,

E-mail: snehswar08@gmail.com

Copyright: () the author(s), publisher and licensee Medip Academy. This is an open-access article distributed under the terms of the Creative Commons Attribution Non-Commercial License, which permits unrestricted non-commercial use, distribution, and reproduction in any medium, provided the original work is properly cited.

\begin{abstract}
Background: Incidence of preterm labour is about 6-15\% of pregnancies worldwide. It is major public health problem in terms of loss of life, long term disability, and health care cost both in developing and developed countries. The incidence of preterm births in India is estimated to be 11-14\% which means about 3 to 4 million preterm live births annually. Early identification of at risk pregnant women with timely referral will help to decrease the extreme prematurity rate, thereby reducing morbidity, mortality and will have a profound impact on societal and long-term public healthcare costs. So this study where vaginal progesterone was administered in women with short cervix detected by Transvaginal sonography to prevent preterm labour will be helpful in decreasing cases with preterm delivery and hence improve the perinatal outcome.

Methods: It is prospective observational study in which 100 ANC patients who were registered at KEM Hospital a tertiary care centre in Mumbai in India at 16-24 weeks of gestation were studied to determine usefulness of $200 \mathrm{mg}$ vaginal progesterone twice daily till 36 weeks in preventing preterm birth in those having cervical length $25 \mathrm{~mm}$ or less.

Results: Among 100 participants in this study, $48(48 \%)$ were primigravida and $52(52 \%)$ were multigravida. Out of $48 \%$ primigravida in the present study, preterm labour is prevented in $75 \%$ of women by the use of vaginal progesterone and out of $52 \%$ of multigravida, it is prevented in $71.2 \%$ of women.

Conclusions: The study concluded that use of vaginal progesterone $200 \mathrm{mg}$ in women with cervical length $25 \mathrm{~mm}$ or less measured by transvaginal sonography (as a good predictor of preterm labour) has useful effect in preventing preterm labour as well as associated neonatal mortality and morbidity. Neonatal survival is critically dependent on maturity of an infant and progressively increases with gestational age. Each day critically impacts on maturity and survival. Thus prevention and/or effective management of preterm labour will improve neonatal outcome and will have a profound impact on societal and long-term public healthcare costs.
\end{abstract}

Keywords: Preterm labour, Transvaginal sonography, Cervical length, Progesterone

\section{INTRODUCTION}

Preterm labour is the onset of painful uterine contractions with effective dilatation and effacement of cervix before 37 completed weeks of gestation. Incidence of preterm labour is about $6-15 \%$ of pregnancies worldwide. ${ }^{1}$ It is major health problem related to common man in terms of loss of life, disability, and health care cost both in developing and developed countries. The incidence of preterm births in India is estimated to be $11-14 \%$. Prematurity remains the major cause of perinatal morbidity and mortality According to the World Health Organization, 3 million new-borns die per year because of obstetric complications and $99 \%$ of these deaths occur in developing countries. For those infants who survive there are many health implications like RDS, intraventricular hemorrhage and periventricular leukomalacia, with cerebral dysfunction, infectious 
morbidity, and specific neonatal conditions associated with prematurity, including retinopathy and necrotising enterocolitis.

Preterm births are not only associated with increased perinatal morbidity and mortality but also neurological long term sequele and adverse respiratory system involvement. ${ }^{2}$ In developing countries the problem appears to be in a greater proportion because of poor socioeconomic conditions, as poor personal hygiene, illiteracy, and other factors which ultimately increases the risk of genitourinary tract infections and ultimately leading to preterm labour. Preterm birth is the cause of at least two-thirds of early infant deaths i.e. $60 \%$ of perinatal mortality and long-term neurologic sequele like cerebral palsy and is associated with increase in the number of NICU admissions, severe morbidity in the early neonatal period, prolonged hospital stay after birth and readmission to hospital during infancy.

Idiopathic causes account for approximately $45-50 \%$ of preterm births, $30 \%$ are related to preterm rupture of membranes (PROM) and another $15-20 \%$ is due to elective preterm deliveries due to medical reasons. Risk factors for preterm labour are Previous preterm delivery Cervical incompetence, Infections, Congenital Uterine anomalies, Lower socioeconomic class, Cigarette smoking, Multiple pregnancy.

Defining risk factors for prognostication of preterm birth is a justifiable goal for several reasons. First high risk women need to be identified and this allows initiation of risk-specific treatment. Second, the risk factors might help in identifying a cohort useful for evaluating interventions. Finally, identification of risk factors might provide important insight into mechanisms leading to preterm birth.

\section{Predictors of preterm labour}

Preterm labor may occur spontaneously or following PPROM in $75 \%$ of cases and many attempts have been made to develop methods which may be able to prognosticate the onset of preterm labor so that measures could be taken to prevent its occurrence. These include maternal risk factors, screening for bacterial vaginosis (BV), screening for fetal fibronectin, Home uterine activity monitoring (HUAM), salivary estriol, cervical ultrasonography i.e. cervical length assessment.

\section{Cervical ultrasonography (cervical length assessment)}

Cervix plays a dual role in pregnancy. It maintains the uterine contents against the effects of gravity and intrauterine pressure until labor and dilates to allow the passage of these contents during delivery. Cervical competency depends on its physical integrity as well as the biochemical composition (ground substance) of the cervix. One of the earliest indicators of cervical incompetency or onset of labor is shortening of the cervix
.A short cervix often occurs when there is cervical ripening; A short cervix is syndromic in nature and can be caused by various etiopathologies ${ }^{3}$ such as: connective tissue deficiency after a cervical operation such as conization or loop electrical excision procedure (LEEP) Congenital disorder such as cervical hypoplasia after diethylstilboestrol exposure; Intrauterine infection; decline in progesterone action, cervical disorder that manifests as the clinical presentation of 'Incompetent cervix'.

These causes could be affected by genetic or environmental factors. Sometimes more than one mechanism of disease may be operative in a patient. The length of the cervix may be useful in predicting the risk of premature delivery, with a shorter cervix predicting a greater risk. Routine per-vaginal examination of the cervix for its ripening is the traditional method is now found to be unsatisfactory because this standard method, suffers from large variation among examiners. ${ }^{4}$ In contrast, transvaginal ultrasonography is a reproducible method of examination during pregnancy. ${ }^{5,6}$ Interest in the assessment of cervical length using ultrasound as a predictor of preterm labor arose after Iams et al established the normal distribution of cervical lengths after 22 weeks of gestation. ${ }^{7}$

Cervical assessment by ultrasound has been for the prognostication of spontaneous preterm birth. ${ }^{8}$ The most effective and objective method is transvaginal sonography which is a predictive variable that can be measured as cervical length. The weeks of gestation at which transvaginal ultrasound (TVU) cervical length is most predictive of preterm birth is 14 to 34 weeks, but shortening at any gestational age is also predictive of preterm labour. Before 14 weeks the lower uterine segment is not formed as yet hence it is difficult to differentiate it from the endocervical canal. Therefore, the evaluation of exact length of the cervix is difficult before 14 weeks. The shorter the cervical canal length, the greater is the risk of preterm delivery. ${ }^{9}$

The earlier in gestation the shortening is detected, the higher the risk. This prediction has been confirmed in all populations screened with transvaginal ultrasound so far, including all those at risk of preterm labour like multiple gestations, history of prior preterm birth, mullerian anomalies, cervical surgery and also those with premature rupture of membranes. In fact, cervical length by transvaginal ultrasound is one of the best predictors of preterm birth in all populations studied so far. The sensitivity and specificity differs according to cut-off used for cervical length $25 \mathrm{~mm}$ versus $15 \mathrm{~mm}$; gestational age at the time of screening; population studied. Its positive predictive value also differs depending on the prevalence of preterm labour in the population studied. A short cervical length is usually straight and the presence of curved cervix generally signifies a cervical length greater than $25 \mathrm{~mm}$ and therefore is a reassuring finding. ${ }^{7,10}$ If the cervical canal is closed, cervical length 
is probably the only parameter that requires to be measured. The internal os width greater than $5 \mathrm{~mm}$ should be assessed to determine whether funnelling is present. If funnelling is present the shape can be recorded. ${ }^{11}$ A continuous process of funnelling which progresses from a normal $\mathrm{T}$ shape, to $\mathrm{Y}$, then $\mathrm{V}$, and finally a $U$ shape has been described in literature. It appears that $U$ shape is most of the times associated with preterm delivery, compared with a V -shaped funnel.

Many parameters other than cervical length and presence or absence of a funnel have been studied including funnel width and length, endocervical canal dilation, cervical index (funnel length $+1 /$ functional length), anterior and posterior cervical width in AP view, cervical angle, cervical canal contour, cervical gland area (CGA) and others. $^{12}$

\section{Aims and objectives}

1. To study the usefulness of transvaginal sonography at 16-24 weeks of gestation to assess the cervical length, in predicting the risk of preterm labour.

2. To administer vaginal progesterone $200 \mathrm{mg}$ twice daily, to those having short cervix (cervical length 25 $\mathrm{mm}$ or less), daily till 36 weeks for preventing preterm birth.

3. Thus reducing perinatal morbidity and mortality.

4. To evaluate effect of vaginal progesterone $200 \mathrm{mg}$ twice daily in women with cervical length of $25 \mathrm{~mm}$ or less for preventing preterm birth.

\section{METHODS}

It is prospective observational study in which 100 ANC registered patients at 16-24 weeks of gestation were studied to determine usefulness of $200 \mathrm{mg}$ vaginal progesterone twice daily till 36 weeks in preventing preterm birth in those having short cervix, cervical length $25 \mathrm{~mm}$ or less.

\section{Inclusion criteria}

ANC registered patient, with first trimester ultrasonography available for accurate gestational age and cervical length of $25 \mathrm{~mm}$ or less on transvaginal sonography

\section{Exclusion criteria}

Multiple pregnancies, patients developing any risk factors or requiring early delivery for any other obstetrics indications, Women whose current pregnancy is associated with cervical incompetence, current preterm prelabour rupture of membranes, Known lethal fetal anomaly and fetal demise

\section{RESULTS}

\section{Demographic features}

\section{Distribution of the cases according to obstetric history}

Among 100 participants in this study, 48 (48\%) were primigravida and $52(52 \%)$ are multigravida as shown in the following table and graph.

Table 1: Parity distribution.

\begin{tabular}{|lll|}
\hline Obstetric history & No. & Percentage \\
\hline Primi & 48 & $48.0 \%$ \\
\hline Multigravida & 52 & $52.0 \%$ \\
\hline Total & 100 & $100.0 \%$ \\
\hline
\end{tabular}

In this study of 100 pregnant women, the mean age of participant found to be 25.57 years with minimum of 18 years and maximum of 38 years, standard deviation being 4.4 .

Table 2: Multiple variables and their correlation with preterm labour.

\begin{tabular}{|lllll|}
\hline Variables & Mean & SD & Minimum & Maximum \\
\hline Age (yrs) & 25.57 & 4.41 & 18.00 & 38.00 \\
\hline $\begin{array}{l}\text { Gestational } \\
\text { age at } \\
\text { intervention } \\
\text { (wks) }\end{array}$ & 20.84 & 1.93 & 16.00 & 25.30 \\
\hline $\begin{array}{l}\text { Cervical } \\
\text { length on } \\
\text { TVS (mm) }\end{array}$ & 19.26 & 4.51 & 11.00 & 25.00 \\
\hline $\begin{array}{l}\text { Period of } \\
\text { Progesterone } \\
\text { administration } \\
\text { (wks) }\end{array}$ & 13.53 & 2.10 & 9.00 & 18.00 \\
\hline $\begin{array}{l}\text { Weeks of } \\
\text { gestation at } \\
\text { delivery }\end{array}$ & 35.25 & 2.06 & 31.00 & 40.00 \\
\hline $\begin{array}{l}\text { Birth weight } \\
\text { (gms) }\end{array}$ & 2328.48 & 463.03 & 1250.00 & 3638.00 \\
\hline
\end{tabular}

The mean gestational age at which vaginal progesterone was administered is 20.84 weeks, minimum of 16 weeks and maximum of 25.3 weeks with a standard deviation 1.93 .

The maximum cervical length on transvaginal ultrasound found to be $25 \mathrm{~mm}$ and minimum of $11 \mathrm{~mm}$. The mean and standard deviation being $19.26 \mathrm{~mm}$ and 4.51 respectively

Similarly mean and standard deviation for the total period of use of vaginal progesterone is 13.53 weeks and 2.10 respectively with minimum of 9 weeks and maximum 18 weeks. The mean gestational age at the time of delivery in the present study found to be 35.25 weeks with the use of vaginal progesterone to women with short cervix. Minimum gestational age was 31 weeks and maximum 
was 40 weeks with standard deviation 2.06 . The mean birth weight was 2328.48 grams with minimum 1250 grams and maximum 3638 grams.

In group where cervical length less than $15 \mathrm{~mm}$ by TVS, pregnancy is carried till term successfully in $69.2 \%$ of women and similarly in $74.3 \%$ women where cervical length is $15 \mathrm{~mm}$ and more by the use of vaginal progesterone.

Table 3: The co-relation of cervical length to gestational age at the time of delivery.

\begin{tabular}{|c|c|c|c|c|}
\hline \multirow{2}{*}{$\begin{array}{l}\text { Cervical } \\
\text { length on } \\
\text { TVS } \\
(\mathrm{mm})\end{array}$} & & \multicolumn{2}{|c|}{ Gestation at delivery } & \multirow[b]{2}{*}{ Total } \\
\hline & & Preterm & Term & \\
\hline \multirow[t]{2}{*}{$<15$} & No. & 8 & 18 & 26 \\
\hline & $\%$ & $30.8 \%$ & $69.2 \%$ & $100.0 \%$ \\
\hline \multirow[t]{2}{*}{$15 \&>$} & No. & 19 & 55 & 74 \\
\hline & $\%$ & $25.7 \%$ & $74.3 \%$ & $100.0 \%$ \\
\hline \multirow[t]{2}{*}{ Total } & No. & 27 & 73 & 100 \\
\hline & $\%$ & $27.0 \%$ & $73.0 \%$ & $100.0 \%$ \\
\hline
\end{tabular}

$30.8 \%$ and $25.7 \%$ preterm birth is observed in a group of cervical length less than $15 \mathrm{~mm}$ and another group of $15 \mathrm{~mm}$ and more cervical length respectively despite the use of vaginal progesterone as shown in Table 3.

Table 4: Comparison of various variables in preterm and term cases.

\begin{tabular}{|c|c|c|c|}
\hline \multirow[t]{2}{*}{ Variables } & \multicolumn{3}{|c|}{ Unpaired t-test applied } \\
\hline & t-value & p-value & Difference \\
\hline $\operatorname{Age}(\mathrm{yrs})^{\wedge}$ & -0.187 & 0.852 & Not significant \\
\hline $\begin{array}{l}\text { Gestational } \\
\text { age at } \\
\text { intervention } \\
(w k s)^{\wedge}\end{array}$ & -0.372 & 0.71 & Not significant \\
\hline $\begin{array}{l}\text { Cervical } \\
\text { length on TVS } \\
(\mathrm{mm})^{\wedge}\end{array}$ & -3.835 & 0.00013 & Significant \\
\hline $\begin{array}{l}\text { Period of } \\
\text { progesterone } \\
\text { administration } \\
(\mathrm{wks})^{\wedge}\end{array}$ & -4.027 & $\begin{array}{l}5.66 \text { E- } \\
05\end{array}$ & Significant \\
\hline $\begin{array}{l}\text { Weeks of } \\
\text { gestation at } \\
\text { delivery }^{\wedge}\end{array}$ & -7.681 & $\begin{array}{l}1.58 \mathrm{E}- \\
14\end{array}$ & Significant \\
\hline $\begin{array}{l}\text { Birth weight } \\
\text { (gms) }\end{array}$ & -10.622 & $\begin{array}{l}5.42 \mathrm{E}- \\
18\end{array}$ & Significant \\
\hline
\end{tabular}

Thus applying the test of significance to the present data, the significant variables found to be cervical length, period of progesterone administration, weeks of gestation at the time of delivery and birth weight. It suggests that giving a vaginal progesterone $200 \mathrm{mg}$ in women having cervical length $25 \mathrm{~mm}$ or less on transvaginal sonography has significance in terms of weeks of gestational age at delivery and birth weight of neonate irrespective of age of pregnant woman and gestational age at which progesterone has administered.

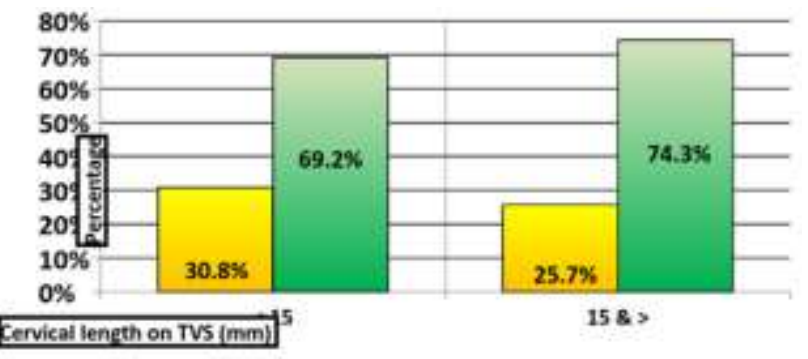

Figure 1: Correlation of cervical length to gestational age at the time of delivery.

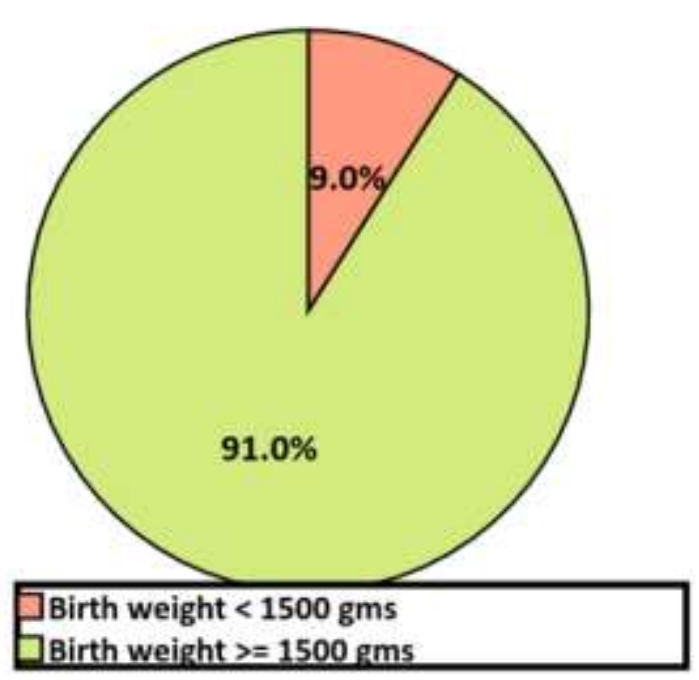

Figure 2: Birth weight less than 1500 gms.

Table 5: Distribution of cases according to need of NICU admission.

\begin{tabular}{|c|c|c|}
\hline NICU admission & No. & Percentage \\
\hline Yes & 22 & $22.0 \%$ \\
\hline No & 78 & $78.0 \%$ \\
\hline Total & 100 & $100.0 \%$ \\
\hline
\end{tabular}

\section{DISCUSSION}

Preterm birth is a well-known cause of infant mortality and morbidity in the developing as well as developed countries. Although the survival rates are greatly improved, morbidity associated with being born too soon and too small remains high. Infants born preterm are over 40 times more likely to die during the neonatal period than are term infants, and the risk is higher for infants born at earlier gestational ages, this increased risk of mortality persists even for infants born before 34 weeks gestation. While preterm birth contributes a relatively small proportion of total births, it is associated with in more than of $70 \%$ of the total perinatal mortality in 
developed countries, when excluding deaths related to congenital anomalies. ${ }^{13}$

For surviving infants, there are significant health implications, respiratory distress syndrome due to immature lungs, is the most significant cause of early neonatal mortality and morbidity. Significant proportion of infants requires mechanical ventilation, up to $20 \%$ of surviving infants remain dependent on oxygen therapy 28 days after birth whereas $25 \%$ diagnosed with chronic lung disease. Health complications include intra cerebral bleed, leukomalacia, causing cerebral dysfunction, infectious morbidity, retrolental fibroplasia and necrotising enterocolitis. Preterm Infants are at increased risk of hospitalization in the first year of life. In the longer-term, increased risks of motor and sensory impairment, and subsequent handicap, including cerebral palsy. ${ }^{13}$ Additionally infants born preterm have well recognized learning difficulties, behavioural problems and poor scholastic performance.

The study was done on 100 participants attending the hospital for routine antenatal O.P.D. Cervical length was done by transvaginal sonography between 16 to 24 weeks of gestation at the time of malformation scan and vaginal progesterone was administered to women with cervical length of $25 \mathrm{~mm}$ or less. Observations regarding weeks of gestation at the time of delivery, need of NICU admission for baby or any neonatal complications were made as outcome of the study.

Among 100 participants in this study, 48 (48\%) were primigravida and $52(52 \%)$ were multigravida. Out of $48 \%$ primigravida in the present study, preterm labor is prevented in $75 \%$ of women by the use of vaginal progesterone and out of $52 \%$ of multigravida, it is prevented in $71.2 \%$ of women. Preterm delivery rate in primigravida is $25 \%$ and $28.8 \%$ in multigravida. Overall in $73 \%$ of pregnant women of short cervix (cervical length $<25 \mathrm{~mm}$ by transvaginal ultrasound), preterm birth is prevented by use of vaginal progesterone but despite of the use of vaginal progesterone $27 \%$ delivered preterm.

In this study of 100 pregnant women, $13(13 \%)$ are of 18 years and less age group, $83(83 \%)$ are of $19-34$ age group and $4(4 \%)$ are of age group of 35 years and more. The mean age of participant found to be 25.57 years with minimum of 18 years and maximum of 38 years, standard deviation being 4.4. In the present study vaginal progesterone has prevented preterm labor in $76.9 \%$, $71.1 \%$ and $100 \%$ in age group of 18 years and less, 19-34 years and 35 years and more respectively. The maximum cervical length on transvaginal ultrasound found to be $25 \mathrm{~mm}$ and minimum of $11 \mathrm{~mm}$. The mean and standard deviation being $19.26 \mathrm{~mm}$ and $4.51 \mathrm{~mm}$ respectively. In group where cervical length less than $15 \mathrm{~mm}$ by transvaginal ultrasound, pregnancy is carried till term successfully in $69.2 \%$ of women and similarly in $74.3 \%$ women where cervical length is $15 \mathrm{~mm}$ and more by the use of vaginal progesterone. $30.8 \%$ and $25.7 \%$ preterm birth is observed in a group of cervical length less than 15 $\mathrm{mm}$ and another group of $15 \mathrm{~mm}$ and more cervical length respectively despite the use of vaginal progesterone. In Fonseca EB study shows spontaneous delivery before 34 weeks of gestation was rarely seen in the progesterone group than in placebo group (19.2\% vs. $34.4 \%$; relative risk, 0.56 ; $95 \%$ confidence interval $[\mathrm{CI}], 0.36$ to 0.86 ). Progesterone was associated with a non-significant fall in neonatal morbidity $(8.1 \%$ vs. $13.8 \% ; \mathrm{P}=0.17)$. There were no serious side effects progesterone uses.

Out of 413 pregnant women in Eduardo B. Fonseca Study, use of vaginal progesterone prevented preterm labour in 334 ( $80.9 \%$ ) women as compare to 73 out of $100(73 \%)$ in present study. Comparison between two studies by Chi-Square test gives p value of 0.0811 that is non-significant difference

Hassan SS study shows that administration of vaginal progesterone gel to women with a sonographic short cervix in the midtrimester is associated with a $45 \%$ reduction in the rate of preterm birth before 33 weeks of gestation and with improved neonatal outcome, Vaginal progesterone was also associated with a significant reduction in the rate of preterm birth before 28 weeks. ${ }^{16}$

In Hassan SS Study, Out of 458 pregnant women, use of vaginal progesterone prevented preterm labour in 392 ( $85.6 \%$ ) women as compared to 73 out of $100(73 \%)$ in present study. Thus these two studies are comparable statistically as shown above.

The mean gestational age at the time of delivery in the present study found to be 35.25 weeks with the use of vaginal progesterone to women with short cervix. Minimum gestational age was 31 weeks and maximum was 40 weeks with standard deviation 2.06.

Out of 100 births in this study $9(9 \%)$ are low birth weight $(<1500 \mathrm{gms})$ and $91(91 \%)$ have birth weight 1500 gms and more. The mean birth weight was 2328.48 grams with minimum 1250 grams and maximum 3638 grams. Of the total 100 infants born, only $22(22 \%)$ required NICU admission for further care and 78 (78\%) did not require the same. Amongst the 100 infants born only $8(8 \%)$ had neonatal complication whereas $92(92 \%)$ were free from the same.

\section{CONCLUSION}

The mean gestational age at which vaginal progesterone was administered is 20.84 weeks, minimum of 16 weeks and maximum of 25.3 weeks is suggestive of "earlier the use of vaginal progesterone less the chances of preterm labour".

The maximum cervical length on transvaginal found to be $25 \mathrm{~mm}$ and minimum of $11 \mathrm{~mm}$. The mean of $19.26 \mathrm{~mm}$ and showed that short cervix $(<25 \mathrm{~mm})$ is good predictor of preterm labour. 
Similarly mean for the total period of use of vaginal progesterone is 13.53 weeks with minimum of 9 weeks and maximum 18 weeks, suggestive of "more the use of vaginal progesterone less the chances of preterm labour".

The mean gestational age at the time of delivery in the present study found to be 35.25 weeks with the use of vaginal progesterone to women with short cervix. Minimum gestational age was 31 weeks and maximum was 40 weeks suggesting that use of vaginal progesterone has significant role in prevention of preterm labour as well as associated neonatal mortality and morbidity in women with short cervix.

The study concluded that use of vaginal progesterone 200 $\mathrm{mg}$ in women with cervical length $25 \mathrm{~mm}$ or less measured by transvaginal sonography (as a good predictor of preterm labour) has useful effect in preventing preterm labour thereby reducing neonatal mortality and morbidity.

Funding: No funding sources

Conflict of interest: None declared

Ethical approval: The study was approved by the Institutional Ethics Committee

\section{REFERENCES}

1. Slattery MM, Morrison JJ. Preterm delivery. Lancet. 2002;360(9344):1489-97.

2. ABC of Labour Care, Preterm Labour and Premature Rupture of Membranes, Philip Steer, Caroline Flint; BMJ. 1999:318.

3. Romero R. The child is the father of the man. Prenat Neonat Med. 1996;1:8-11.

4. Holcomb WL Jr, Smeltzer JS. Cervical effacement: variation in belief among clinicians. Obstet Gynecol. 1991;78:43-5.

5. Sonek JD, Iams JD, Blumenfeld M, Johnson F, Landon M, Gabbe S. Measurement of cervical length in pregnancy: comparison between vaginal ultrasonography and digital examination. Obstet Gynecol. 1990;76:172-5.

6. Andersen HF. Transvaginal and transabdominal ultrasonography of the uterine cervix during pregnancy. J Clin Ultrasound. 1991;19:77-83.

7. Iams JD, Goldenberg RL, Meis PJ. The length of cervix and the risk of spontaneous preterm delivery.
National Institute of Child Health and Human Development Maternal Fetal Medicine Unit Network. N Engl J Med. 1996;334:567-72.

8. Berghella V, Bega G, Tolosa JE, Berghella M. Ultrasound assessment of the cervix. Clinical Obstetrics and Gynecology. 2003;46:947-62.

9. Grimes-Dennis J, Berghella V. Cervical length and prediction of preterm birth. Current Opinion in Obstetrics and Gynecology. 2007;19:191-5.

10. Owen J, Yost N, Berghella V, Thom E, Swain M, Dildy GA, et al. Mid-trimester endovaginal sonography in women at high risk for spontaneous preterm birth. JAMA. 2001;286:1340-8.

11. To MS, Skentou C, Liao AW, Cacho A, Nicolaides $\mathrm{KH}$. Cervical length and funneling at 23 weeks of gestation in the prediction of spontaneous early preterm delivery. Ultrasound Obstet Gynecol. 2001;18:200-3.

12. Fukami $T$, Ishihara $K$, Sekiya $T$, Araki $T$. Is transvaginal ultrasonography at mid-trimester useful for predicting early spontaneous preterm birth? J Nippon Med Sch. 2003;70:135-40.

13. Mattison DR, Damus K, Fiore E, Petrini J, Alter C. Preterm delivery: a public health perspective. Paediatric and Perinatal Epidemiology. 2001;15(Suppl. 2):7-16.

14. Stanley F. Survival and cerebral palsy in low birth weight infants implications for Perinatal care. Paediatr Perinat Epidemiol. 1992;6:298-310.

15. DeFranco EA, O'Brien JM, Adair CD. Vaginal progesterone is associated with a decrease in risk for early preterm birth and improved neonatal outcome in women with a short cervix: a secondary analysis from a randomized, double-blind, placebo-controlled trial. Ultrasound Obstet Gynecol. 2007;30(5):697705.

16. Hassan SS, Romero R, Vidyadhari D. Vaginal progesterone reduces the rate of preterm birth in women with a sonographic short cervix: a multicenter, randomized, double-blind, placebocontrolled trial Ultrasound Obstet Gynecol. 2011;38:18-31.

Cite this article as: Rajeshwari RR, Rubini M. Maternal and perinatal outcome in placenta previa one year study in tertiary care center in Tamil Nadu, India. Int J Reprod Contracept Obstet Gynecol 2016;5:2813-8. 